\title{
Metadherin regulates radioresistance in cervical cancer cells
}

\author{
YING ZHAO $^{1}$, MEENA S. MORAN ${ }^{2}$, QIFENG YANG ${ }^{3}$, QIAO LIU ${ }^{4}$, \\ CUNZHONG YUAN $^{1}$, SHUHUI HONG ${ }^{5}$ and BEIHUA KONG ${ }^{1}$
}

\author{
${ }^{1}$ Department of Obstetrics and Gynecology, Qilu Hospital of Shandong University, Ji'nan, Shandong 250012, \\ P.R. China; ${ }^{2}$ Department of Therapeutic Radiology, Yale University School of Medicine, New Haven, CT, USA; \\ ${ }^{3}$ Department of Breast Surgery, Qilu Hospital of Shandong University, Ji'nan, Shandong 250012; ${ }^{4}$ Institute of Molecular \\ Medicine and Genetics and Key Laboratory of Experimental Teratology, Ministry of Education, Shandong \\ University School of Medicine, Ji'nan, Shandong 250012; ${ }^{5}$ Department of Obstetrics and Gynecology, \\ Affiliated Qianfoshan Hospital of Shandong University, Ji'nan, Shandong 250014, P.R. China
}

Received November 14, 2011; Accepted December 19, 2011

DOI: $10.3892 /$ or.2012.1692

\begin{abstract}
Metadherin (MTDH) promotes cancer metastasis, chemoresistance, invasion and angiogenesis. Upregulation of MTDH is correlated with both progression and poor clinical outcome of many types of cancers; however, there is currently no information regarding the role of MTDH in radiation sensitivity. Here, we investigated the effects of MTDH on the radiosensitivity of cervical cancer cells using the SiHa cell line. We discovered that cervical cancer cells in which MTDH was knocked down had significantly increased radiosensitivity as measured by a clonogenic assay. MTDH knockdown cells also had increased apoptosis and a decreased proportion of cells arrested in the $\mathrm{G} 2$ phase after radiation treatment. MTDH knockdown also weakened the repair of DNA double-strand breaks (DSBs) induced by radiation. These results indicate that MTDH affects the radiosensitivity of cervical cancer cells and that MTDH may be a novel target to improve cervical cancer radiation response.
\end{abstract}

\section{Introduction}

Cervical cancer is one of the most common cancers in women worldwide. There are approximately 500,000 new cervical cancer cases in the world each year, and more than $80 \%$ of these cases occur in developing countries $(1,2)$. The current management for cervical cancer consists primarily of surgery, radiation and chemotherapy. The combination of external beam radiotherapy and intracavitary brachytherapy is regarded as the standard treatment for cervical cancer (3). Intracavitary

Correspondence to: Dr Beihua Kong, Department of Obstetrics and Gynecology, Qilu Hospital of Shandong University, 107 West Wenhua Road, Ji'nan, Shandong 250012, P.R. China

E-mail: kongbeihua@yahoo.com.cn

Key words: metadherin, radiosensitivity, cell cycle, apoptosis, DNA double-strand breaks repair brachytherapy allows for the delivery of higher doses of radiation to the tumor with less exposure to normal tissue (4). While definitive radiotherapy has high cure rates in early stage disease, the survival rates in locally advanced cervical cancer cases remains poor, with a 5-year overall survival of only $66 \%$ (5). Therefore, more effective strategies for the treatment of locally advanced cervical cancer need to be discovered.

Many genetic alterations, such as EGFR, c-erbB-2 and COX-2, have been discovered to be associated with survival and/ or response to chemo- and radiotherapy (6). Previous studies have shown that EGFR expression decreased radiosensitivity of cervical cancer (7-9). Moreover, inhibition of EGFR with cetuximab plus radiotherapy increased overall survival when compared with the use of radiotherapy alone (10). Metadherin (MTDH, also known as AEG-1) was originally reported as a protein induced in primary human fetal astrocytes infected with HIV-1 or treated with either HIV gp120 or TNF- $\alpha(11,12)$. MTDH synergizes with oncogenic Ha-ras to enhance the softagar-colony-forming ability of non-tumorigenic immortalized melanocytes (13). Recently, clinical studies have revealed that MTDH is overexpressed in various malignancies, including breast, prostate, glioma, hepatocellular, and esophageal cancer and is associated with disease progression and poor clinical outcomes (14). Moreover, MTDH has been found to promote cancer metastasis, chemoresistance, invasion and angiogenesis (15-21), suggesting that it may function as an oncogene. Furthermore, MTDH knockdown has been found to sensitize breast cancer and neuroblastoma cells to cisplatin $(15,17)$. Cisplatin is a platinol systemic agent that is widely used in the treatment of bladder, ovarian, cervical, testicular, and head and neck cancer (22). Cisplatin can cause cross-links in DNA (23). Therefore, based on the speculation that MTDH may similarly impact the radiosensitivity of cancer cells, we studied the role of MTDH in radioresistance.

In this study, we downregulated the expression of MTDH in a cervical cancer cell line ( $\mathrm{SiHa}$ ) and measured cell survival with a clonogenic assay. We discovered that knockdown of MTDH increased the radiosensitivity of SiHa to X-ray, and we further investigated the mechanism by which MTDH affects the radiosensitivity of cancer cells. 


\section{Materials and methods}

Cell culture. The human cervical squamous carcinoma cell line SiHa (24) [American Type Culture Collection (ATCC) Manassas, VA, USA] was routinely maintained in Minimum Essential Medium (MEM, Invitrogen, Carlsbad, CA, USA) and supplemented with $10 \%$ fetal bovine serum (FBS, Haoyang Biological Manufacture Co., Ltd., Tianjin, China), $100 \mathrm{U} / \mathrm{ml}$ penicillin and $100 \mu \mathrm{g} / \mathrm{ml}$ streptomycin at $37^{\circ} \mathrm{C}$ in an atmosphere of $5 \% \mathrm{CO}_{2}$.

Irradiation. The cells were irradiated at room temperature using a Faxitron Cabinet X-ray System (Faxitron, Wheeling, IL, USA) at a dose rate of $0.36 \mathrm{~Gy} / \mathrm{min}$. The X-rays were filtered through a 0.5 -mm aluminum filter.

Construction of stably transfected cell lines. Endogenous MTDH was knocked down using the pSUPER.retro.puro vector containing short hairpin RNA (shRNA) against MTDH. The shRNA oligonucleotide sequence was ATGAACCAGAA TCAGTCAGC. The cells were transfected with either shRNA against MTDH or a control vector using Lipofectamine 2000 (Invitrogen) according to the manufacturer's instructions, and mixed resistant clones were collected and cultured in medium containing puromycin (Invitrogen). Western blot analysis was used to detect the expression of MTDH in all of the cell lines described above.

Cell viability test. Cell viability was evaluated using the clonogenic assay. Briefly, exponentially growing cells were seeded into 6-well plates (400 cells/well) (Costar, Corning, NY, USA) and incubated for $12 \mathrm{~h}$ to allow the cells to attach. The cells were then irradiated with increasing fraction size $(0,1,2,3$ and $4 \mathrm{~Gy})$ and cultured for 12 days. The colonies were fixed with methanol for $30 \mathrm{~min}$ and stained with crystal violet. Colonies containing more than 50 cells were counted. The surviving fraction was calculated as follows: (number of colonies formed)/(number of cells plated x plating efficiency), and the plating efficiency was defined as: (number of colonies formed)/(number of cells plated for non-irradiated controls). Experiments were performed in triplicate and repeated three times.

Cell cycle analysis. To investigate cell cycle alterations after irradiation, cells $\left(30-40 \times 10^{5}\right)$ were plated on $60-\mathrm{mm}$ culture dishes (BD Biosciences, San Jose, CA, USA) overnight and irradiated with the indicated doses. Cells were then harvested by digestion with $0.25 \%$ trypsin and washed twice with phosphate-buffered saline (PBS). Subsequently, $1 \times 10^{6}$ cells were resuspended in 1-ml staining solution $(50 \mu \mathrm{g} / \mathrm{ml}$ PI, $20 \mu \mathrm{g} /$ $\mathrm{ml}$ RNase A) and incubated for $30 \mathrm{~min}$ at room temperature protected from light and filtered using a 300-mesh nylon meshwork prior to detection. The DNA content was analyzed by flow cytometry with a FACScalibur (BD Biosciences). The results from 10,000 cells were analyzed with the ModFit software.

Apoptosis analysis. Cells $\left(20-30 \times 10^{5}\right)$ were plated on $60-\mathrm{mm}$ culture dishes overnight and irradiated with the indicated doses. Proportions of apoptotic cells with/without irradiation were detected by flow cytometry using the Annexin V-FITC Apoptosis Detection Kit (BD Biosciences). The experiment was performed according to the manufacturer's protocol. Floating cells were collected, and the attached cells were trypsinized and washed twice with ice-cold PBS at the indicated time. Then $1 \times 10^{5}$ cells were resuspended in $100 \mu \mathrm{l} 1 \mathrm{X}$ binding buffer, and $5 \mu \mathrm{l}$ of Annexin V-FITC and $5 \mu \mathrm{l}$ of PI were added following incubation for $15 \mathrm{~min}$ at room temperature protected from light. Finally, $400 \mu \mathrm{l}$ of $1 \mathrm{X}$ binding buffer was added to each sample. The samples were analyzed by flow cytometry within $1 \mathrm{~h}$ using the FACScalibur (BD Biosciences) with the CellQuest software. Cells that stained positive for FITC Annexin V and negative for PI were identified as apoptotic cells.

Immunofluorescence. Cells were irradiated with $0.5 \mathrm{~Gy}$ after attaching to chamber slides (Nest, Wuxi, China) in 12-well plates. At 0, 0.5, 2, 4 and $8 \mathrm{~h}$ post-irradiation, the cells were washed in PBS three times and fixed in 4\% paraformaldehyde for $15 \mathrm{~min}$ at room temperature. The cells were then permeabilized in $0.2 \%$ Triton X-100 for 8 min after washing four times in PBS and blocked with $10 \%$ goat serum in PBS overnight at $4^{\circ} \mathrm{C}$, followed by incubation with mouse anti-human phosphoHistone H2AX monoclonal antibody (Millipore, Billerica, MA, USA) diluted 1:500 overnight at $4^{\circ} \mathrm{C}$. After being washed three times with PBS, the cells were incubated with Rhodaminelabeled secondary antibody (KPL, Gaithersburg, MD, USA) at room temperature for $1 \mathrm{~h}$ in the dark. The secondary antibody solution was removed, and the cells were washed with PBS three times before counterstaining with $1 \mu \mathrm{g} / \mathrm{ml}$ DAPI for 5 min in the dark. Finally, the slides were mounted with an antifading reagent and examined with a Leica fluorescence microscope.

Western blot assay. The cells were washed in PBS and lysed in RIPA buffer (Shennengbocai, Shanghai, China) (1\% NP-40, $0.1 \%$ SDS, $5 \mathrm{mM}$ EDTA, $0.5 \%$ sodium deoxycholate and $1 \mathrm{mM}$ sodium vanadate) containing protease inhibitors (1 mM PMSF, $1 \mathrm{mM}$ sodium fluoride). The samples were incubated on ice for $30 \mathrm{~min}$ and centrifuged at 12,000 $\mathrm{x}$ g for $15 \mathrm{~min}$ at $4^{\circ} \mathrm{C}$. The supernatants were collected, and the protein concentration was measured with the BCA Protein Assay kit (Merck, Darmstadt, Germany). An equal amount of total protein was separated by $10 \%$ sodium lauryl sulfate-polyacrylamide gel electrophoresis (SDS-PAGE) and electroblotted onto a PVDF membrane (Millipore) using a semi-dry blotting apparatus (Bio-Rad Laboratories, Hercules, CA, USA). Membranes were blocked in 5\% non-fat milk in TBST at room temperature for $1 \mathrm{~h}$, incubated overnight with primary antibodies at $4^{\circ} \mathrm{C}$ and then washed three times with TBST. This was followed by an additional $2 \mathrm{~h}$ of incubation with HRP-labeled secondary antibodies (KPL, Gaithersburg, MD, USA) in blocking buffer $(1: 5,000)$. Finally, the membranes were washed three times with TBST, and the protein bands were detected using an ECL system (Merck, Darmstadt, Germany) according to the manufacturer's instructions. The primary antibodies included MTDH (1:500, Abcam, Cambridge, MA, USA), Bcl-2 (1:200, Dako, Carpinteria, CA, USA), Ku70, Ku80, DNA-PKcs, Rad51 (1:200, Santa Cruz Biotechnology, Santa Cruz, CA USA) and $\beta$-actin (1:5,000, Sigma-Aldrich, St. Louis, MO, USA). 
$\mathbf{A}$

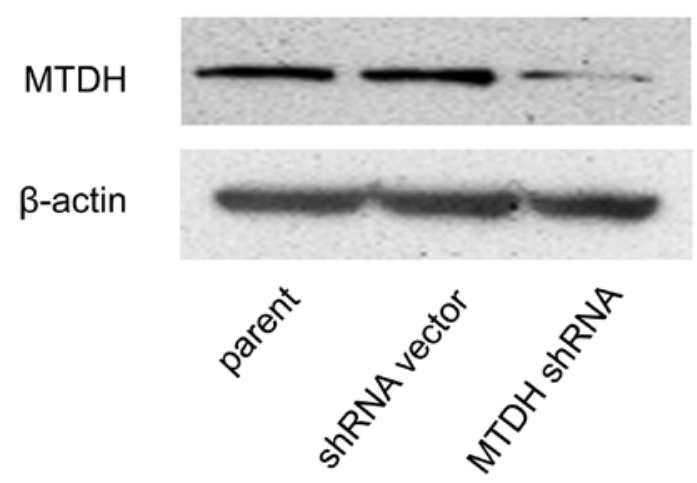

B

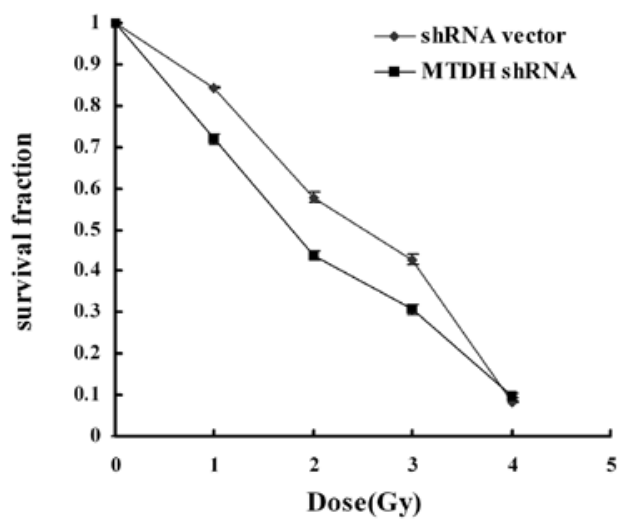

Figure 1. Knockdown of MTDH increases the X-ray radiosensitivity of SiHa cells. (A) The expression of MTDH in SiHa cells and their derivative cell lines was examined by western blot analysis. (B) Cell viability was evaluated using the clonogenic assay. A marked difference in the surviving fraction was observed between $\mathrm{SiHa} / \mathrm{shRNA}$ vector and $\mathrm{SiHa} / \mathrm{MTDH}$ shRNA cells $(\mathrm{P}<0.05)$. Data shown are the mean $\pm \mathrm{SD}$ of three independent experiments.

Statistical analysis. The results were analyzed using SPSS 16.0 software (Chicago, IL, USA). Each experiment was performed three times, and the data were expressed as the mean \pm SD. The two-tailed Student's t-test was used to analyze the differences between the means, and a P-value of $<0.05$ was considered significant.

\section{Results}

Knockdown of MTDH increases the radiosensitivity of SiHa cells. To knock down MTDH, we transfected SiHa cells with MTDH shRNA and obtained stable cell lines. The expression of MTDH in SiHa and its derivative cell lines was examined by western blot analysis. As shown in Fig. 1A, cells transfected with MTDH shRNA had significantly decreased levels of MTDH compared to the control groups.

A clonogenic assay was performed to determine the effect of MTDH on the radiosensitivity of cervical cancer cell lines. Radiation caused a dose-dependent decrease in the survival of all SiHa lines. As shown in Fig. 1B, knockdown of MTDH in $\mathrm{SiHa}$ markedly increased the cells' susceptibility to X-ray radiation. The surviving fractions of the $\mathrm{SiHa} / \mathrm{shRNA}$ vector after 1,2, 3 and 4 Gy of X-ray radiation were 84, 58, 43 and $8 \%$, respectively, while the surviving fractions of $\mathrm{SiHa} / \mathrm{MTDH}$ shRNA were $72 \%(\mathrm{P}<0.05), 44 \%(\mathrm{P}<0.01), 31 \%(\mathrm{P}<0.01)$ and $10 \%$ after radiation treatment.

Knockdown of MTDH decreases $G 2$ phase arrest induced by $X$-ray radiation. Cell cycle distribution after irradiation was assessed by PI staining. As shown in Fig. 2A, radiation induces $\mathrm{G} 2$ phase arrest of $\mathrm{SiHa}$ cells. At $10 \mathrm{~h}$ post-radiation, $38 \%$ of $\mathrm{SiHa} / \mathrm{shRNA}$ vector cells were arrested in the G2 phase when receiving 2 Gy of $\mathrm{X}$-ray radiation, while only $33 \%(\mathrm{P}<0.01)$ of $\mathrm{SiHa} / \mathrm{MTDH}$ shRNA cells arrested in the $\mathrm{G} 2$ phase at the same time after being treated with an equivalent dose of X-rays. The proportion of $\mathrm{SiHa} / \mathrm{shRNA}$ vector and $\mathrm{SiHa} / \mathrm{MTDH}$ shRNA cells that arrested in $\mathrm{G} 2$ phase without radiation was equal (Fig. 2B).

Knockdown of MTDH increases radiation-induced apoptosis. We evaluated the frequency of apoptotic cells using Annexin V/PI staining at $24 \mathrm{~h}$ after X-ray radiation. The percentage of apoptotic cells was $\sim 10$ and $13 \%(\mathrm{P}<0.05)$ in $\mathrm{SiHa} / \mathrm{shRNA}$ vector and $\mathrm{SiHa} / \mathrm{MTDH}$ shRNA cells, respectively, after exposure to 2 Gy of X-ray radiation (Table I). Knockdown of MTDH itself did not change the proportion of apoptotic cells in the $\mathrm{SiHa}$ cell line; the proportion of apoptotic cells was 3.51 and $4.75 \%$ ( $>0.05)$ before and after silencing of MTDH, respectively, indicating that the increased radiosensitivity accompanying knockdown of MTDH was related to the increased apoptosis induced by radiation.

MTDH modulates the levels of Bcl-2 after radiation. To evaluate the mechanism underlying the radioprotection conferred by MTDH expression, the expression of Bcl-2 (an anti-apoptotic protein) in both $\mathrm{SiHa} / \mathrm{shRNA}$ vector and $\mathrm{SiHa} /$ MTDH shRNA cells was determined in cells with or without radiation treatment. As shown in Fig. 3B, while there was no significant change in the basal levels of Bcl-2 in the two groups of cells ( $\mathrm{P}>0.05)$, delivery of $2 \mathrm{~Gy}$ induced a significant upregulation in $\mathrm{Bcl}-2$ expression in $\mathrm{SiHa} / \mathrm{shRNA}$ vector cells

Table I. Percentage of early apoptotic cells in Annexin V/PI staining assay.

\begin{tabular}{|c|c|c|c|}
\hline shRNA vector 0 Gy & MTDH shRNA 0 Gy & shRNA vector $2 \mathrm{~Gy}$ & MTDH shRNA 2 Gy \\
\hline $3.51 \pm 0.50 \%$ & $4.75 \pm 0.25 \%$ & $9.90 \pm 0.28 \%$ & $12.59 \pm 0.52 \%$ \\
\hline
\end{tabular}


A

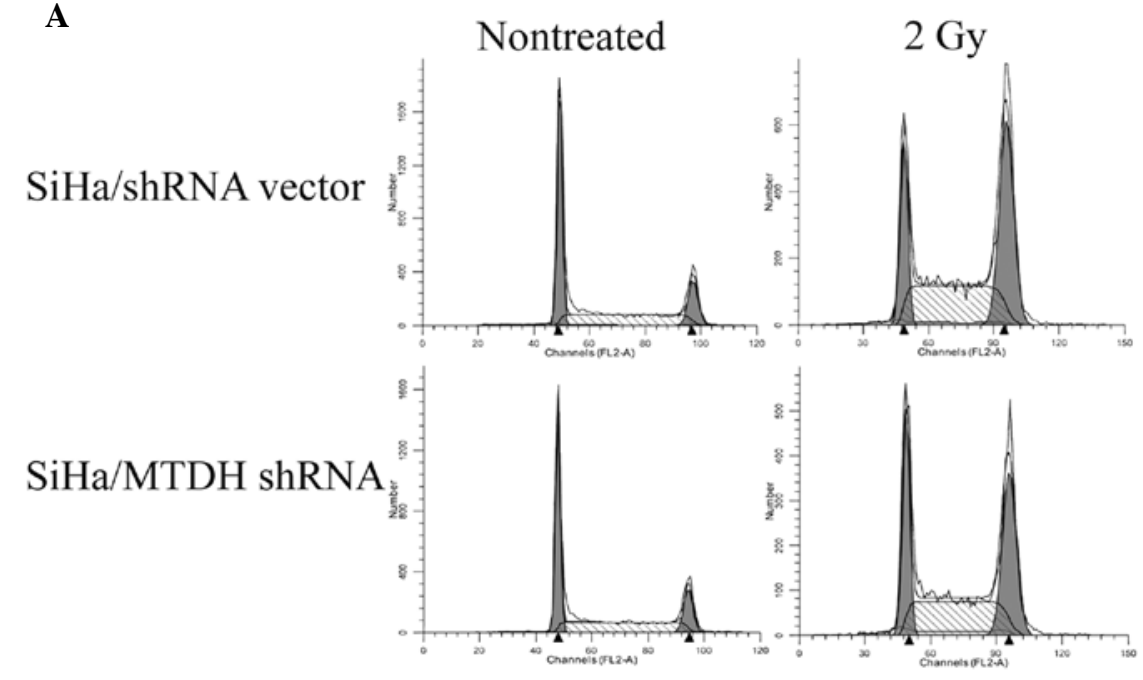

B

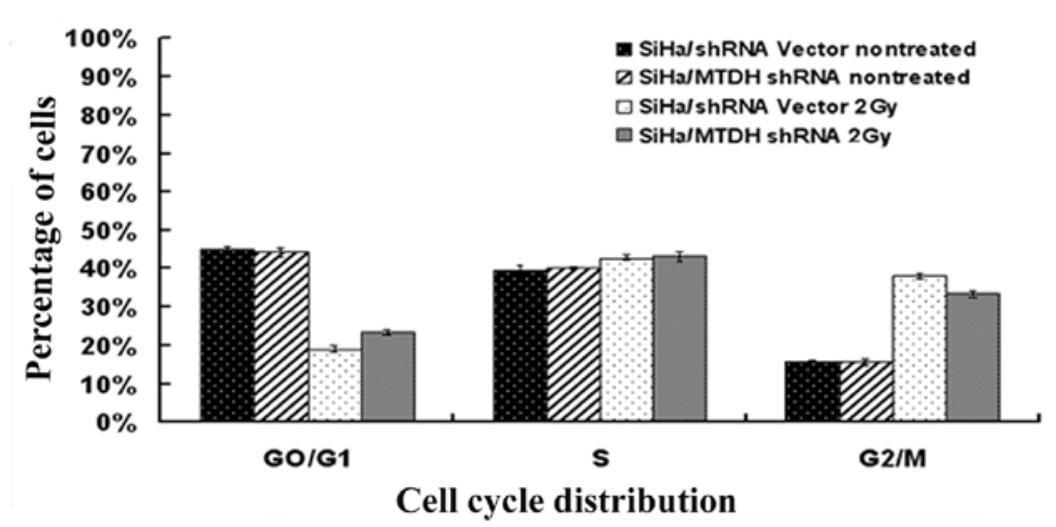

Figure 2. Cell cycle distribution by flow cytometry and the levels of Bcl-2 as measured by western blot analysis. (A) Knockdown of MTDH in SiHa cells decreased cell arrest in the G2 phase after radiation $(\mathrm{P}<0.01)$. The percent of $\mathrm{SiHa} / \mathrm{shRNA}$ vector and $\mathrm{SiHa} / \mathrm{MTDH}$ shRNA cells that arrested in G2 phase without radiation was equal.
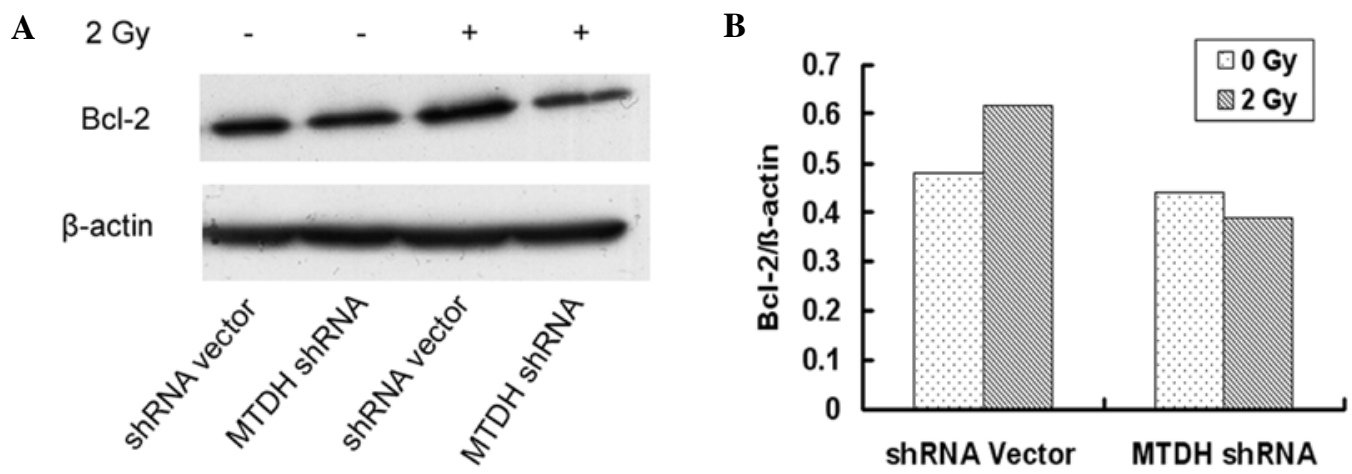

Figure 3. (A) Expression of Bcl-2 by western blot analysis. (B) The expression of Bcl-2 in SiHa/shRNA vector cells after 2 Gy of X-rays was upregulated compared with $\mathrm{SiHa} / \mathrm{MTDH}$ shRNA cells exposed to an equivalent dose of radiation $(\mathrm{P}<0.01)$, while there was no significant change of the levels of $\mathrm{Bcl}-2$ in the two cell lines without radiation $(\mathrm{P}>0.05)$.

$(\mathrm{P}<0.01)$. By contrast, radiation-induced upregulation of Bcl-2 was not observed in SiHa/MTDH shRNA cells.

MTDH enhanced the repair of DSBs after irradiation. A DNA double-strand break (DSB) is considered the most common and lethal type of radiation-induced damage (25). Phosphorylation of $\mathrm{H} 2 \mathrm{AX}(\gamma-\mathrm{H} 2 \mathrm{AX})$, which leads to the formation of foci at sites of DSBs, marks an early step in the cellular response to DSBs (26). The persistence of $\gamma-\mathrm{H} 2 \mathrm{AX}$ foci after irradiation reflects an impaired cellular capacity to repair DSBs $(27,28)$. We scored the $\gamma$-H2AX foci at different time points after the delivery of a single fraction of $0.5 \mathrm{~Gy}$. While many foci emerged after radiation, the foci disappeared faster in the SiHa/shRNA vector cells, with the vast majority 
A

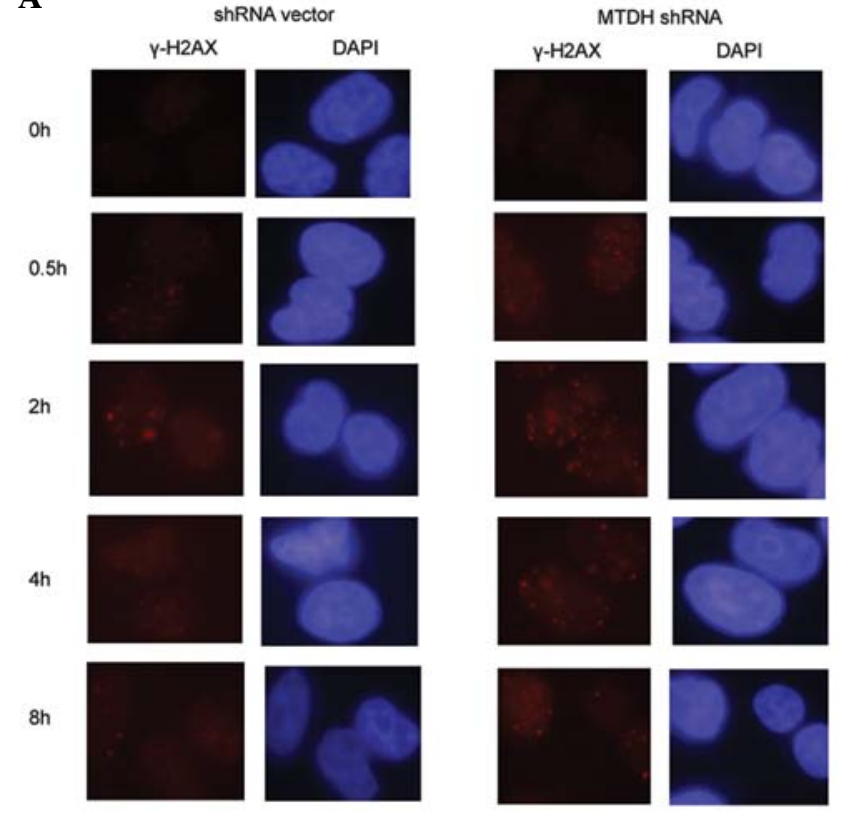

B

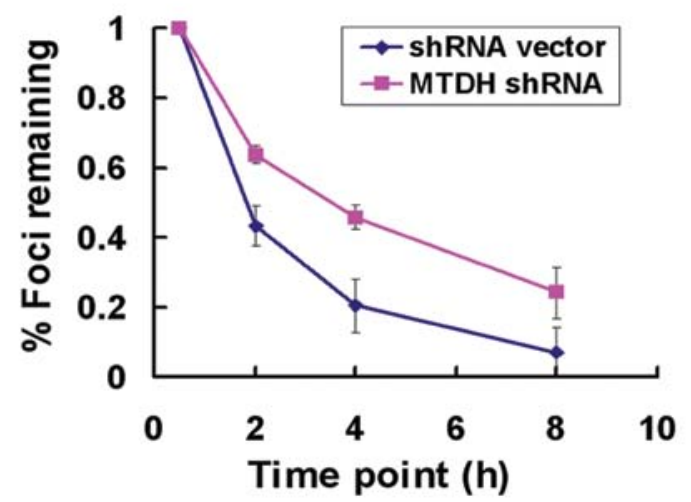

Figure 4. MTDH enhanced the capacity of cells to repair radiation-induced DNA DSBs. (A) Images of $\gamma$-H2AX foci at $0,0.5,2,4$ and $8 \mathrm{~h}$ after $0.5 \mathrm{~Gy}$ of X-rays using immunofluorescence. (B) The percent of foci remaining represents the number of foci at the indicated time compared with that at $0.5 \mathrm{~h}$.

disappearing at $4 \mathrm{~h}$ post-radiation, in comparison to the $\mathrm{SiHa} /$ MTDH shRNA cells (Fig. 4), where the foci persisted for up to $8 \mathrm{~h}$ post-radiation. These results suggest that MTDH may play a role in enhancing the capacity of cells to repair radiationinduced DNA DSBs.

To investigate the mechanism by which MTDH promotes the repair of DSBs, we examined expression of DSB repair proteins Ku70, Ku80, DNA-PKcs and Rad51 by western blot analysis. As shown in Fig. 5, knockdown of MTDH resulted in a downregulation of Ku70 in SiHa cells, whereas no change was observed in the expression of the other repair proteins (Ku80, DNA-PKcs and Rad51). Therefore, MTDH likely promotes the repair of radiation-induced DSBs, mainly through the upregulation of $\mathrm{Ku} 70$.

\section{Discussion}

MTDH was initially identified as a human astrocyte gene that was elevated after either infection with HIV-1 or exposure to the

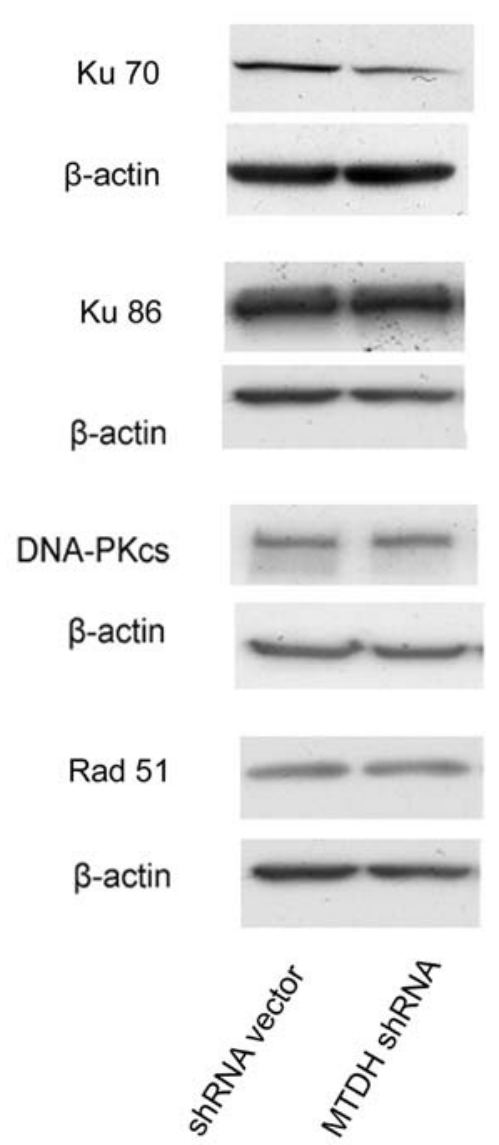

Figure 5. The proteins involved in the DSB repair pathway were examined by western blot analysis. Knockdown of MTDH resulted in downregulation of $\mathrm{Ku} 70$. No change was detected in the expression of other DSB repair proteins.

viral glycoprotein gp120 (11). MTDH was found to be located at $8 \mathrm{q} 22$, a site of recurrent amplification in human gliomas and breast cancers; the full-length cDNA consists of $3611 \mathrm{bp}$ encoding a 582 amino acid protein $(13,15)$. In recent years, an increasing number of publications indicate that MTDH plays an important role in cancer progression and development. Our study is one of the first to evaluate the relationship of MTDH with radiation, and our findings demonstrate that cervical cancer cells are more sensitive to radiation following knockdown of MTDH. The increased radiosensitivity may be related to the disruption of cell cycle arrest, downregulation of anti-apoptotic genes and/or impairment of DNA DSB repair.

Irradiation results in a delay of progression through the G1, $\mathrm{S}$ and G2 phases of the cell cycle. The G2 arrest portion of the cell cycle is protective against radiation because the cells have more time to repair DNA damage and prevent cell death $(29,30)$. In our study, the proportion of cells that were arrested in $\mathrm{G} 2$ phase after radiation was lower when MTDH was downregulated than in the control group.

Bcl-2 is an anti-apoptotic protein that plays an important role in radiation-induced apoptosis. Inhibition of $\mathrm{Bcl}-2$ enhances radiation-induced apoptosis (31). Our results indicated that knockdown of MTDH generated more apoptotic cells after radiation and that Bcl-2 expression was lower in MTDH knockdown cells than in control cells, suggesting that the radioprotective effect of MTDH may be mediated via Bcl-2 modulation. 
Radiation generates a variety of DNA lesions including base damages, single-strand breaks, DSBs and DNA-protein crosslinks. DSBs can cause genomic instability leading to either cell death or carcinogenesis (32). H2AX is a subset of the core histone $\mathrm{H} 2 \mathrm{~A}$, and its phosphorylation $(\gamma-\mathrm{H} 2 \mathrm{AX})$ occurs rapidly after DSBs $(33,34)$. The $\gamma$-H2AX foci caused by low-dose radiation in cells with MTDH knocked down were present longer than in the parental cells, indicating that MTDH may promote DSB repair as a potential mechanism of MTDHassociated radioresistance.

In mammalian cells, homologous recombination (HR) and DNA non-homologous end-joining (NHEJ) are two major DSB repair mechanisms $(35,36)$. NHEJ is the main pathway to repair DSBs after radiation, while HR plays a minor role in repairing radiation-induced DSBs in adult cells $(37,38)$. The proteins involved in NHEJ include Ku70, Ku80 and DNA-PKcs, which together compose the DNA-dependent protein kinase complex (DNA-PK) $(38,39)$. In our study, knockdown of MTDH decreased the expression of Ku70, indicating that MTDH may enhance DSB repair and lead to radioresistance through the impairment of NHEJ.

In conclusion, we found that knockdown of MTDH increased the radiosensitivity of cervical cancer cells. MTDH levels may therefore be a useful marker for the predication of radiation response of cervical cancers and could be used as a novel target to increase the radiosensitivity of cervical cancer cells.

\section{Acknowledgements}

This study was supported by the National Basic Research Program of China (2011CB966200), National Natural Science Foundation of China (nos. 30872738; 30772133; 81001166), and by the Natural Science Foundation of Shandong Province (ZR2009CL015; ZR2010HQ050).

\section{References}

1. Ferlay J, Shin HR, Bray F, Forman D, Mathers C and Parkin DM: Estimates of worldwide burden of cancer in 2008: GLOBOCAN 2008. Int J Cancer 127: 2893-2917, 2010.

2. Garland SM, Cuzick J, Domingo EJ, et al: Recommendations for cervical cancer prevention in Asia Pacific. Vaccine 26 (Suppl 12) M89-M98, 2008

3. Nakano T, Kato S, Ohno T, et al: Long-term results of high-dose rate intracavitary brachytherapy for squamous cell carcinoma of the uterine cervix. Cancer 103: 92-101, 2005.

4. Nakano T, Ohno T, Ishikawa H, Suzuki $\mathrm{Y}$ and Takahashi T: Current advancement in radiation therapy for uterine cervical cancer. J Radiat Res (Tokyo) 51: 1-8, 2010.

5. Cochrane Gynaecological Cancer Group: Reducing uncertainties about the effects of chemoradiotherapy for cervical cancer: individual patient data meta-analysis. Cochrane Database Systematic Rev CD008285, 2010.

6. Noordhuis MG, Eijsink JJ, Roossink F, et al: Prognostic cell biological markers in cervical cancer patients primarily treated with (chemo)radiation: a systematic review. Int J Radiat Oncol Biol Phys 79: 325-334, 2011.

7. Fuchs I, Vorsteher N, Buhler H, et al: The prognostic significance of human epidermal growth factor receptor correlations in squamous cell cervical carcinoma. Anticancer Res 27: 959-963, 2007.

8. Gaffney DK, Haslam D, Tsodikov A, et al: Epidermal growth factor receptor (EGFR) and vascular endothelial growth factor (VEGF) negatively affect overall survival in carcinoma of the cervix treated with radiotherapy. Int J Radiat Oncol Biol Phys 56: 922-928, 2003
9. Kedzia W, Schmidt M, Frankowski A and Spaczynski M Immunohistochemical assay of p53, cyclin D1, c-erbB2, EGFR and Ki-67 proteins in HPV-positive and HPV-negative cervical cancers. Folia Histochem Cytobiol 40: 37-41, 2002.

10. Bonner JA, Harari PM, Giralt J, et al: Radiotherapy plus cetuximab for squamous-cell carcinoma of the head and neck. N Engl J Med 354: 567-578, 2006

11. Su ZZ, Kang DC, Chen Y, et al: Identification and cloning of human astrocyte genes displaying elevated expression after infection with HIV-1 or exposure to HIV-1 envelope glycoprotein by rapid subtraction hybridization, $\mathrm{RaSH}$. Oncogene 21: 3592-3602, 2002.

12. Su ZZ, Chen Y, Kang DC, et al: Customized rapid subtraction hybridization $(\mathrm{RaSH})$ gene microarrays identify overlapping expression changes in human fetal astrocytes resulting from human immunodeficiency virus-1 infection or tumor necrosis factor-alpha treatment. Gene 306: 67-78, 2003.

13. Kang DC, Su ZZ, Sarkar D, Emdad L, Volsky DJ and Fisher PB: Cloning and characterization of HIV-1-inducible astrocyte elevated gene-1, AEG-1. Gene 353: 8-15, 2005.

14. Hu G, Wei Y and Kang Y: The multifaceted role of MTDH/ AEG-1 in cancer progression. Clin Cancer Res 15: 5615-5620, 2009.

15. Hu G, Chong RA, Yang Q, et al: MTDH activation by $8 \mathrm{q} 22$ genomic gain promotes chemoresistance and metastasis of poorprognosis breast cancer. Cancer Cell 15: 9-20, 2009.

16. Brown DM and Ruoslahti E: Metadherin, a cell surface protein in breast tumors that mediates lung metastasis. Cancer Cell 5: 365-374, 2004

17. Liu H, Song X, Liu C, Xie L, Wei L and Sun R: Knockdown of astrocyte elevated gene-1 inhibits proliferation and enhancing chemo-sensitivity to cisplatin or doxorubicin in neuroblastoma cells. J Exp Clin Cancer Res 28: 19, 2009.

18. Yoo BK, Emdad L, Su ZZ, et al: Astrocyte elevated gene-1 regulates hepatocellular carcinoma development and progression. J Clin Invest 119: 465-477, 2009.

19. Yu C, Chen K, Zheng $\mathrm{H}$, et al:Overexpression of astrocyte elevated gene-1 (AEG-1) is associated with esophageal squamous cell carcinoma (ESCC) progression and pathogenesis. Carcinogenesis 30: 894-901, 2009.

20. Emdad L, Sarkar D, Lee SG, et al: Astrocyte elevated gene-1: a novel target for human glioma therapy. Mol Cancer Ther 9: 79-88, 2010.

21. Emdad L, Lee SG, Su ZZ, et al: Astrocyte elevated gene-1 (AEG-1) functions as an oncogene and regulates angiogenesis. Proc Natl Acad Sci USA 106: 21300-21305, 2009.

22. O'Dwyer PJ, Stevenson JP and Johnson SW: Clinical pharmacokinetics and administration of established platinum drugs. Drugs 59 (Suppl 4): 19-27, 2000.

23. Osieka R and Schmidt CG: Cis-diamminedichloroplatinum(II). A new antineoplastic agent derived from the group of heavy metal complexes. Klin Wochenschr 57: 1249-1258, 1979 (In German).

24. Friedl F, Kimura I, Osato T and Ito Y: Studies on a new human cell line ( $\mathrm{SiHa}$ ) derived from carcinoma of uterus. I. Its establishment and morphology. Proc Soc Exp Biol Med 135: 543-545, 1970.

25. Hoeijmakers JH: Genome maintenance mechanisms for preventing cancer. Nature 411: 366-374, 2001.

26. Rogakou EP, Pilch DR, Orr AH, Ivanova VS and Bonner WM: DNA double-stranded breaks induce histone H2AX phosphorylation on serine 139. J Biol Chem 273: 5858-5868, 1998.

27. Rothkamm K and Lobrich M: Evidence for a lack of DNA double-strand break repair in human cells exposed to very low x-ray doses. Proc Natl Acad Sci USA 100: 5057-5062, 2003.

28. Bouquet F, Muller C and Salles B: The loss of $\gamma \mathrm{H} 2 \mathrm{AX}$ signal is a marker of DNA double strand breaks repair only at low levels of DNA damage. Cell Cycle 5: 1116-1122, 2006.

29. McKenna WG, Weiss MC, Endlich B, et al: Synergistic effect of the v-myc oncogene with H-ras on radioresistance. Cancer Res 50: $97-102,1990$

30. Kong Z, Xie D, Boike T, et al: Downregulation of human DAB2IP gene expression in prostate cancer cells results in resistance to ionizing radiation. Cancer Res 70: 2829-2839, 2010.

31. Zerp SF, Stoter R, Kuipers G, et al: AT-101, a small molecule inhibitor of anti-apoptotic Bcl-2 family members, activates the SAPK/JNK pathway and enhances radiation-induced apoptosis. Radiat Oncol 4: 47, 2009.

32. Kobayashi J, Iwabuchi K, Miyagawa K, et al: Current topics in DNA double-strand break repair. J Radiat Res (Tokyo) 49: 93-103, 2008 
33. Thiriet $\mathrm{C}$ and Hayes JJ: Chromatin in need of a fix: phosphorylation of H2AX connects chromatin to DNA repair. Mol Cell 18: 617-622, 2005

34. Foster ER and Downs JA: Histone H2A phosphorylation in DNA double-strand break repair. FEBS J 272: 3231-3240, 2005.

35. Essers J, van Steeg H, de Wit J, et al: Homologous and nonhomologous recombination differentially affect DNA damage repair in mice. EMBO J 19: 1703-1710, 2000.

36. Hefferin ML and Tomkinson AE: Mechanism of DNA doublestrand break repair by non-homologous end joining. DNA Repair (Amst) 4: 639-648, 2005.
37. Rothkamm K, Kruger I, Thompson LH and Lobrich M: Pathways of DNA double-strand break repair during the mammalian cell cycle. Mol Cell Biol 23: 5706-5715, 2003.

38. Jeggo PA and Lobrich M: Contribution of DNA repair and cell cycle checkpoint arrest to the maintenance of genomic stability. DNA Repair (Amst) 5: 1192-1198, 2006.

39. Van Dyck E, Stasiak AZ, Stasiak A and West SC: Binding of double-strand breaks in DNA by human Rad52 protein. Nature 398: 728-731, 1999. 